\title{
O uso da artroscopia na osteocondrite dissecante da articulação do ombro
}

Julia Maria MATERA ${ }^{1}$

Angélica Cecília

TATARUNAS ${ }^{1}$

Denise Tabacchi FANTONI ${ }^{1}$

Karina Velloso Braga

YAZBEK ${ }^{1}$

\section{Correspondência para:}

JULIAMARIAMATERA

Departamento de Cirurgia

Faculdade de Medicina Veterinária e

Zootecnia

Universidade de São Paulo

Av. Prof. Orlando Marques de Paiva, 87

Cidade Universitária “Armando de Salles

Oliveira"

CEP.: 05508-900 São Paulo - SP

materave@usp.br

Recebido para publicação: 14/11/2003 Aprovado para publicação: 15/03/2005

1 - Departamento de Cirurgia da Faculdade de Medicina Veterinária e Zootecnia da Universidade de São Paulo, São Paulo - SP

\section{Resumo}

O objetivo do trabalho foi avaliar o uso da artroscopia em cães portadores de osteocondrite dissecante da articulação do ombro quanto a visibilização das estruturas intra-articulares, alterações de cartilagem, membrana sinovial e complicações. Durante o procedimento artroscópico ocorreram infiltração periarticular, lesão iatrogênica de cartilagem, dificuldade de confecção dos portais artroscópio, instrumental, realização da triangulação e deslocamento prematuro do artroscópio. A hiperplasia de sinóvia foi presente em todos os animais operados. Lesões cartilagíneas consistiram de condromalácea, erosão, eburnação, osteofito, fibrilação, presença de retalho de cartilagem livre e aderido. A artroscopia trouxe informações importantes quanto ao número e localização dos retalhos e condição geral da articulação. A remoção do retalho de cartilagem por artroscopia é um procedimento que requer maior habilidade do que aquela necessária para a realização da artroscopia diagnóstica, portanto o cirurgião deve ter maior experiência.

\section{Introdução}

Apesar da artroscopia ser amplamente utilizada no diagnóstico e tratamento das afecções articulares no homem e no cavalo, na espécie canina o seu desenvolvimento foi lento e somente nos últimos anos é que ela vem se tornando relevante ${ }^{1,2,3}$. O espaço limitado das pequenas articulações caninas é citado como uma das prováveis causas deste retardo ${ }^{4} \mathrm{e}$, isto associado à complexidade de algumas articulações e a fragilidade dos instrumentos que devem ser manipulados tornam a artroscopia na técnica endoscópica rígida de maior dificuldade ${ }^{5}$.

A artroscopia possibilita uma avaliação das estruturas intra-articulares superior àquela fornecida por uma artrotomia, pois ela associa magnificação da imagem com luminosidade no ambiente líquido natural ${ }^{6,78}$.

$O$ primeiro relato de abordagem da articulação do ombro no cão foi feito por Person', o qual desenvolveu três portais, sendo o do artroscópio localizado craniolateralmente. Posteriormente os pesquisadores passaram a confeccionar o portal artroscópico em posição lateral $(1 \mathrm{a} 2 \mathrm{~cm}$ caudal e $1 \mathrm{~cm}$ distal ao acrômio) ${ }^{10,11,12}$ e o portal instrumental caudal a este ${ }^{10,12}$. Mc Carthy ${ }^{5}$ desenvolveu novo portal para o artroscópio entre dois portais descritos anteriormente, entre o músculo deltóide e o tubérculo maior do úmero, em cuja localização não há sobreposição muscular. Em 2002, Martini, Pinna e Del Bue ${ }^{13}$ e colaboradores, a fim de simplificar as técnicas anteriores, confeccionaram dois portais, um cranial ao ligamento glenoumeral e outro caudal, os quais foram invertidos em sua função de portal artroscópio ou instrumental de acordo com a região a ser tratada.

Em um primeiro trabalho clínico foi realizada a artroscopia em cães portadores de osteocondrite dissecante da articulação do ombro seguida de artrotomia, a fim de confirmar os resultados e remover os fragmentos livres de cartilagem ${ }^{8}$. Em relato subseqüente os autores descreveram a remoção de fragmentos livres de cartilagem em cães portadores desta mesma afecção por via 
1 Hopkins ${ }^{\circledR}$ Forward Oblique Telescope $30^{\circ}-$ Karl Storz GmbH \& Co 2 Arthroscope Sheath-Karl Storz GmbH \& $\mathrm{Co}$

3 Cold Light Fountain Xenon Nova - Karl Storz $\mathrm{GmbH} \&$ Co

4 Xenon Spare Lamp, 175W, 15V - Karl Storz $\mathrm{GmbH} \&$ Co

5 Fluid Light Cables - Karl Storz GmbH \&

6 Color Monitor - Karl Storz GmbH \& Co 7 Telecam ${ }^{\circledR}$ câmera Control Unit-Karl Storz $\mathrm{GmbH} \& \mathrm{Co}$

8 Telecam ${ }^{\circledR}$ Câmera Head - Karl Storz $\mathrm{GmbH} \& \mathrm{Co}$

9 Vídeo Printer - Sony

10 Dimorf - Cristália Prod. Quím. Farm. Ltda

11 Acepran 0.2\% - UNIVET Ltda 12 Propofol - Cristália Prod. Quim. Farm. Ltda.

13 Forane- Produtos Hospitalares Abbott 14 Esmeron - Organon do Brasil

15 Rimady ${ }^{\circledR}$ - Pfizer

16 Dipirona ${ }^{\circledR}$-Geyer Medicamentos S.A 17 Tramal ${ }^{\circledR}$ - Seale Monsanto do Brasil Ltda artroscópica, porém salientaram que o procedimento exigiu habilidade e experiência ${ }^{12}$. Em 1995 Bardet $^{10}$ relatou a exérese com sucesso dos fragmentos de cartilagem da supracitada articulação citando como vantagens da artroscopia rapidez, exploração sistemática da articulação com exame da bainha do tendão bicipital e do compartimento medial, graduação da sinovite e ausência de trauma cirúrgico articular.

A infiltração periarticular pelo líquido de drenagem é a complicação trans-operatória de maior prevalência ${ }^{8,9,10,12}$. Hemorragia ${ }^{9,10}$, lesão neurovascular ${ }^{12}$, secção inadvertida do tendão infraespinhoso e bíceps braquial ${ }^{9}$, escarificação da cartilagem articular ${ }^{8,9,10}$, dificuldades técnicas durante a realização da triangulação ${ }^{8,12}$, criação do portal artroscópico e instrumental, deslocamento do artroscópio ${ }^{8}$, quebra de instrumento e pobre visualização das estruturas anatômicas devido colocação inadequada do instrumental artroscópico também são citadas?.

Durante o procedimento artroscópico são necessários movimentos de flexão, extensão e rotação para a adequada visibilização das estruturas intra-articulares ${ }^{2,10}$.

O objetivo do presente trabalho foi relatar o uso da artroscopia em cães portadores de osteocondrite dissecante da articulação do ombro quanto a visibilização das estruturas intra-articulares, alterações de cartilagem e membrana sinovial e complicações encontradas durante o procedimento.

\section{Materiais e Métodos}

Foram utilizados cães portadores de osteocondrite dissecante da articulação do ombro encaminhados ao Serviço de Cirurgia de Pequenos Animais do Hospital Veterinário da Faculdade de Medicina Veterinária e Zootecnia da Universidade de São Paulo no período de Março de 2002 a Setembro de 2003.

Após exame clínico e radiográfico os animais foram submetidos a artroscopia diagnóstica e tratamento cirúrgico seja por artroscopia e/ou por artrotomia, no mesmo tempo operatório.

Os exames complementares solicitados no pré-operatório foram hemograma, contagem de plaquetas, uréia e creatinina séricas, ALT, fosfatase alcalina e eletrocardiograma.

Durante o exame artroscópico foram avaliadas: - possibilidade de visibilização das estruturas intra-articulares, facilidades e dificuldades inerentes à técnica artroscópica, bem como complicações e recuperação dos animais.

O instrumental utilizado para a artroscopia consistiu de telescópio ${ }^{1}$ de 2.7 $\mathrm{mm}$ e comprimento de trabalho de $18 \mathrm{~cm}$ e ângulo de $30^{\circ}$, uma cânula ${ }^{2}$ de alto fluxo de $4 \mathrm{~mm}$ de diâmetro, um trocarte agudo, um trocarte rombo, pinça com dente, pinça com cesto, sonda e cureta. A fonte de luz $z^{3}$ fria com lâmpada de xenônio ${ }^{4}$ de $175 \mathrm{~W}$, cabo de fibra óptica ${ }^{5}$ de $3 \mathrm{~mm}$ largura e $250 \mathrm{~cm}$ de comprimento, monitor colorido ${ }^{6}$, unidade de controle de câmera ${ }^{7}$ e cabeça da câmera ${ }^{8}$ e instrumental cirúrgico. A documentação do exame artroscópico foi realizada através de videoimpressora?

A técnica anestésica empregada consistiu de administração de morfina ${ }^{10}(0.5$ $\mathrm{mg} / \mathrm{kg}$ IM) associada a acepromazina ${ }^{11}(0,1$ $\mathrm{mg} / \mathrm{kg}$ ) como medicação pré-anestésica. Para a indução anestésica utilizou-se propofol $^{12}(5 \mathrm{mg} / \mathrm{kg}$ IV). Após a intubação orotraqueal, realizou-se a manutenção da anestesia através da administração de isofluorano ${ }^{13}$ em circuito circular fechado. Os animais foram mecanicamente ventilados, através de ventilador ciclado a tempo com pressão controlada, após a administração de rocurônio ${ }^{14}(0,06 \mathrm{mg} / \mathrm{kg} \mathrm{IV})$. Para a monitoração do paciente foram utilizados analisador de gases anestésicos, capnógrafo, oxímetro de pulso, eletrocardiograma e mensuração da pressão arterial de forma não invasiva.

A medicação pós-operatória consistiu de carprofeno ${ }^{15}(2.2 \mathrm{mg} / \mathrm{kg} \mathrm{VO} / 12-12 \mathrm{hs} /$ 10 dias), dipirona ${ }^{16}(25 \mathrm{mg} / \mathrm{kg} \mathrm{VO} / 8-8 \mathrm{hs} /$ 4dias), tramadol ${ }^{17}$ (2 mg/kg VO/8-8hs/ 
Tabela 1 - Relação dos animais portadores de osteocondrite dissecante quanto a raça, idade, sexo, peso, membro acometido e tempo de evolução até o momento do diagnóstico atendidos no Serviço de Cirurgia do HOVET - FMVZ / USP - São Paulo, 2003

\begin{tabular}{ccccccc}
\hline Cão & Raça & Idade $(\mathrm{m})$ & Sexo & Peso $(\mathrm{kg})$ & Membro & Evolução $(\mathrm{m})$ \\
\hline 1 & Pastor Belga & 13 & $\mathrm{M}$ & 35 & $\mathrm{D} / \mathrm{E}$ & 7 \\
2 & Rottweiler & 8 & $\mathrm{M}$ & 38 & $\mathrm{E}$ & 2 \\
3 & Labrador & 7 & $\mathrm{~F}$ & 30 & $\mathrm{D}$ & 3 \\
4 & Rottweiler & 8 & $\mathrm{M}$ & 36 & $\mathrm{E}$ & 3 \\
5 & Border Collie & 8 & $\mathrm{M}$ & 21 & $\mathrm{E}$ & 2 \\
6 & Rottweiller & 6 & $\mathrm{~F}$ & 27 & $\mathrm{D} / \mathrm{E}$ & 1 \\
7 & Golden Retriever & 10 & $\mathrm{M}$ & 28 & $\mathrm{E}$ & 1,5 \\
8 & Labrador & 8 & $\mathrm{M}$ & 30 & $\mathrm{E}$ & 2 \\
9 & Cocker Spaniel & 12 & $\mathrm{M}$ & 15 & $\mathrm{D} / \mathrm{E}$ & 4 \\
10 & Cane Corso & 7 & $\mathrm{~F}$ & 28 & $\mathrm{D}$ & 2 \\
11 & Rottweiler & 12 & $\mathrm{~F}$ & 30 & $\mathrm{E}$ & 6 \\
12 & Rotweiler & 11 & $\mathrm{M}$ & 37 & $\mathrm{D}$ & 4 \\
\hline
\end{tabular}

D: Direito, E: Esquerdo, M: Macho, F: Fêmea, m:meses, kg:kilogramas

3dias) e ampicilina ${ }^{18}$ (22 mg/kg VO/8-8hs/ 7dias).

Após tricotomia ampla da região a extremidade do membro foi protegida com faixa crepe. A anti-sepsia foi confeccionada com álcool e iodo, foram colocados os panos do primeiro campo operatório e utilizou-se campo adesivo ${ }^{19}$.

$O$ animal foi posicionado em decúbito lateral, o membro acometido por cima e com a articulação do ombro em posição neutra $\left(160^{\circ}\right)$.

Identificaram-se os pontos anatômicos relevantes da região: acrômio, tuberosidade maior e tendão do músculo infraespinhoso, e realizou-se artrocentese com aspiração do líquido sinovial através da introdução de uma agulha calibre $30 \times 8$ e seringa de $3 \mathrm{ml}$, craniolateral entre o acrômio e a porção caudal da tuberosidade maior em direção caudomedial. A cápsula articular foi distendida pela injeção de solução fisiológica 0,9\% através da agulha da artrocentese, até ocorrer resistência no embolo da seringa.

A abordagem utilizada para os 18 Ampicilina ${ }^{\circledR}$ - Merck S.A. Industrias Químicas 19 lobanTM-3M Health Care artroscópico fez-se pequena incisão cutânea com lâmina de bisturi $\mathrm{n}^{\circ} 15 \mathrm{em}$ local previamente determinado. Deu-se preferência a utilização do trocarter rombo com a cânula para perfurar a cápsula articular e adentrar à articulação. Concomitante o membro foi tracionado pela extremidade a fim de distender o espaço intra-articular

O extravasamento de líquido após a remoção do trocarte de dentro da cânula certifica a sua posição intra-articular. Um equipo conectado a um frasco de solução fisiológica foi acoplado ao sistema de influxo da cânula.

A agulha utilizada inicialmente para a distenção da articulação permaneceu como via de drenagem desta enquanto a irrigação foi realizada através da cânula do artroscópio.

Com a cânula dentro da articulação, o trocarte foi substituído pelo artroscópio e iniciado o procedimento.

A inspeção sistemática da articulação obedeceu a seguinte seqüência: origem da bainha fibrosa do tendão do músculo bíceps braquial, compartimento medial e compartimento caudal da articulação do ombro, verificando em cada porção a cartilagem articular e a membrana sinovial, bem como os ligamentos intraarticulares. 
Para a confecção do portal do instrumental, introduziu-se agulha calibre 40x12 em local previamente determinado. A sua localização adequada foi confirmada com o artroscópio. Fez-se então incisão de $0,5 \mathrm{~cm}$ adjacente ao ponto de entrada da agulha com o bisturi, de lâmina 15 , iniciando na pele e posteriormente perfurando cápsula articular. A profundidade de penetração da lâmina foi monitorada pelo artroscópio. Através desta incisão introduziu-se o instrumental.

Durante o procedimento cirúrgico endoscópico foram realizados movimentos de flexão, extensão, rotação, abdução e adução da articulação a fim de maximizar a visibilidade da cavidade articular.

Quando da presença de flap de cartilagem este foi removido e o osso subcondral exposto curetado, quer seja por via artroscópica ou por artrotomia. Procurou-se sempre realizar todo o procedimento por via artroscópica.

No fim do procedimento a articulação foi lavada abundantemente com solução fisiológica sob pressão.

A síntese da pele foi realizada com fio de náilon $4-0^{20}$ em pontos simples separados.

A abordagem à região craniolateral da articulação do ombro por tenotomia do músculo infraespinhoso foi baseada no procedimento de $\mathrm{Hohn}^{14}$, quando necessária para a retirada do retalho cartilagíneo.

No pós-operatório o paciente teve o seu espaço físico restringido durante 30 dias, porém com caminhadas curtas diárias que foram aumentando gradativamente. Após este período o animal foi retornando de forma gradativa a sua atividade normal.

Preconizou-se o uso da crioterapia sobre a articulação do ombro nas primeiras 48 horas de pós-operatório, alternando-se 15 minutos de frio com 10 minutos sem o gelo em duas sessões, várias vezes ao dia ${ }^{1}$.

Os cães foram reavaliados com 48 horas e ao $7^{\circ}, 30^{\circ}$ e $60^{\circ}$ dia de pósoperatório.

\section{Resultados}

Foram atendidos 12 cães (Tabela 1 ) portadores de osteocondrite dissecante da articulação do ombro, diagnóstico confirmado por estudo radiográfico após realização de exame clínico. Destes, em 8 foi realizado procedimento cirúrgico ( $\mathrm{n}^{\circ} 1$ a 8 ).

A idade dos animais variou de 6 a 13 meses, sendo 8 machos e 4 fêmeas. As raças acometidas foram Rottweiler, Labrador, Pastor Belga, Golden Retriever, Border Collie, Cocker Spaniel e Cane Corso, o peso dos cães abrangeu de 15 a $38 \mathrm{~kg}$.

O tempo de evolução da doença, do início dos sintomas ao diagnóstico consistiu de 1 a 7 meses.

Todos os animais mostraram sensibilidade à extensão da referida articulação. Os animais $n^{\circ} 8,10$ e 11 apresentaram discreta atrofia da musculatura do membro acometido. Os animais $n^{\circ} 2,10$ e 11 apresentaram impotência funcional intermitente e os demais, claudicação. A afecção foi bilateral nos animais $n^{\circ} 1,6$ e 9 . $O$ membro acometido foi o esquerdo em 6 cães e o direito em 3.

Dentre os 8 animais submetidos a intervenção cirúrgica, em 7 foi realizado artroscopia seguida de artrotomia para a remoção do retalho de cartilagem em um mesmo tempo operatório. No animal $n^{\circ} 3$ a exérese do fragmento cartilagíneo foi realizada por via artroscópica (Figura 1).

Em todos os animais foram observadas as seguintes estruturas intra-articulares durante o procedimento artroscópico: sulco intertubercular, tendão bicipital, cabeça umeral (cranial e caudal), glenóide, ligamento glenoumeral medial e bolsa articular caudal.

Todas as articulações apresentaram uma membrana sinovial bastante vascularizada e vilos hipertrofiados (Figura 2).

As complicações obtidas durante o procedimento artroscópico estão descritas na tabela 2. Dificuldade para a confecção do artroscópio ocorreu em 5 articulações $\left(\mathrm{n}^{\circ} 3,4,5,6\right.$ e 7$)$, sendo que no animal $\mathrm{n}^{\circ} 3$ devido a cápsula articular encontrar-se 


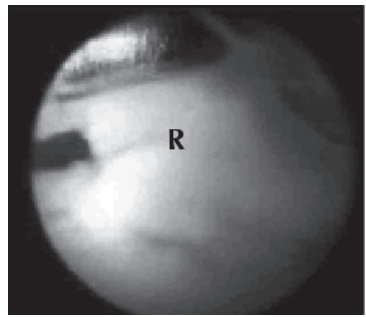

Figura 1 - Remoção do retalho (R) via artroscopia (cão n 3 )

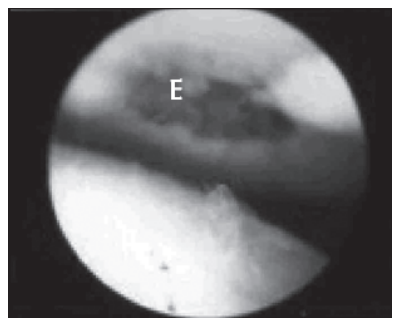

Figura 4 -Erosão (E) de cartilagem na glenóide (cão $n^{\circ}$ 6)

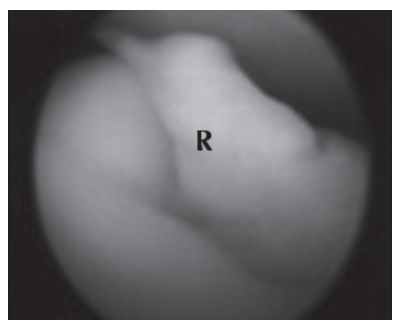

Figura 7 - Retalho de cartilagem (R) aderido na cabeça do úmero (cão no 3 )

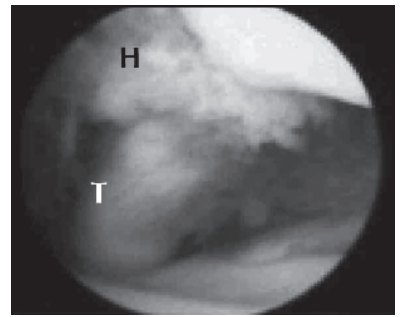

Figura 2 - Hiperplasia de vilos sinoviais (H)em região próximoaotendão bicipital (T) (cão no 5)

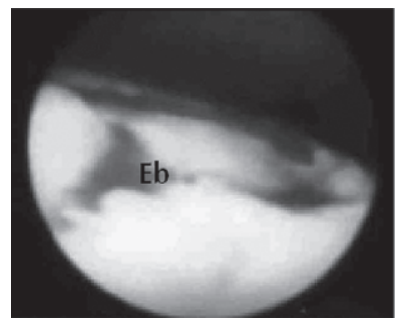

Figura 5 - Eburnação (Eb) na cabeça do úmero (cão nº 8)

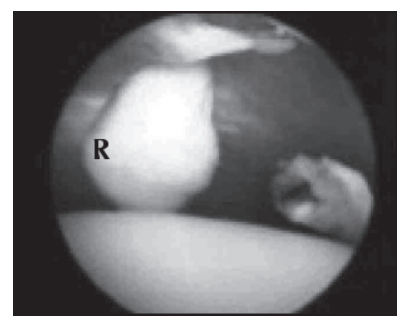

Figura 8 - Retalho de cartilagem (R) livre próximo ao tendão bicipital (cão $n^{\circ} 8$ )

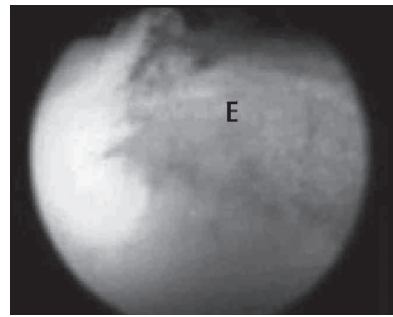

Figura 3 - Erosão (E) de cartilagem na cabeça do úmero (cão nº 7)

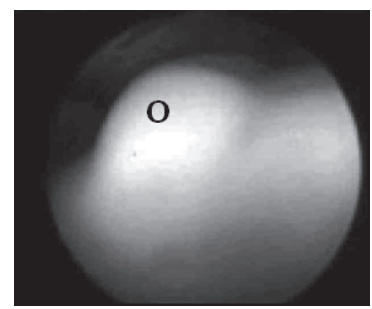

Figura 6 - Osteofito $(O)$ na porção crania da cabeça do úmero (cão ${ }^{\circ}$ 6)

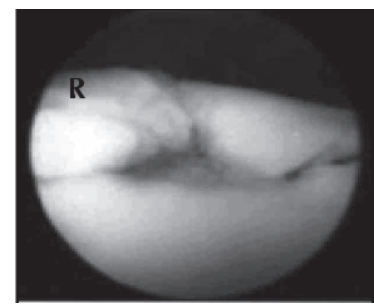

Figura 9 - Retalho de cartilagem (R) livre próximo ao defeito cartilagíneo na cabeça do úmero (cão nº 1 ) bastante espessada fez-se uso de trocarte agudo ao invés do rombo. No animal $n^{\circ} 4$ não foi possível a confecção do portal artroscópico, devido crescente infiltração periarticular e conseqüente dificuldade na individualização dos pontos de referência.

Insucesso na criação do portal instrumental ocorreu em 6 articulações; tal fato deu-se principalmente devido a dificuldade na localização da extremidade da agulha inserida no interior da articulação para a realização da triangulação, pois não raro esta encontrava-se encoberta pelos vilos sinoviais hipertrofiados. No animal $\mathrm{n}^{\circ} 8$ embora a agulha tivesse sido localizada pelo artroscópio no interior da articulação, ocorreu hemorragia durante a incisão da pele e tecido celular subcutâneo com o bisturi e, na tentativa de alterar a posição da agulha houve dificuldade em dispô-la em posição que fosse adequada para a remoção do retalho pelo instrumental.

Ocorreu lesão iatrogênica da cartilagem articular nas articulações n ${ }^{\circ} 5$ e 7 durante a confecção do portal artroscópico, na região da cavidade glenóide. Não se observou qualquer diferença na recuperação destes animais em relação aos demais.

Em todas as articulações houve o deslocamento prematuro do artroscópio, de 2 a 6 vezes por procedimento; principalmente durante a tentativa de triangulação.

$\mathrm{O}$ acúmulo de fluido periarticular foi 
Tabela 2 - Complicações observadas durante o procedimento artroscópico realizado em animais portadores de osteocondrite dissecante no Serviço de Cirurgia do HOVET - FMVZ / USP - São Paulo, 2003

\begin{tabular}{cc}
\hline Complicações & Cão $\left(\mathrm{n}^{0}\right)$ \\
\hline Dificuldade confecção portal artroscópico & $3,4,5,6,7$ \\
Dificuldade confeç̧ão portal instrumental & $1,2,5,6,7,8$ \\
Lesão iatrogênica de cartilagem & 5,7 \\
Deslocamento prematuro artroscópio & $1,2,3,5,6,7,8$ \\
Acúmulo fluído periarticular & $1,2,3,5,6,7,8$ \\
\hline
\end{tabular}

presente nas 8 articulações estudadas, sendo leve nos animais $n^{\circ} 1,5$ e 6 ; médio nos $n^{\circ} 2$, 3,7 e 8 e severo na articulação no 4 . Este teve remissão espontânea em 24 horas.

As lesões cartilagíneas encontradas durante o procedimento artroscópico foram condromalácea nos animais $\mathrm{n}^{\circ} 1,6$, 2, 7, 3 e 5, erosão na cabeça umeral caudal (no 1, 6, 2, 7, 3, e 5) (Figura 3), erosão na cavidade glenóide não iatrogênica $\left(n^{\circ} 6\right)$ (Figura 4), eburnação (ño 6, 7 e 8) (Figura 5), osteofito cabeça umeral cranial $\left(n^{\circ} 6\right)$ (Figura 6) e fibrilação em cabeça umeral em todas as articulações estudadas. Observou-se o retalho de cartilagem aderido ao defeito na cabeça umeral $\left(\mathrm{n}^{\circ} 2,3,5\right)$ (Figura 7$)$, fragmento cartilagíneo livre junto ao defeito na cabeça umeral ( $\mathrm{n}^{\circ}$ 1) (Figura 8), livre próximo a bainha do tendão bicipital $\left(\mathrm{n}^{\circ} \mathrm{G}\right.$, 7 e 8) (Figura 9), livre na bolsa caudal da articulação $\left(n^{\circ} 5\right)$ e livre na porção medial da articulação $\left(n^{\circ} 6\right)$. As articulações $n^{\circ} 5$ e 6 apresentaram mais de um fragmento de cartilagem livre no interior da articulação.

Todos os animais apoiaram o membro com 24 horas de pós-operatório sendo a claudicação ausente com 30 dias de pós-operatório, exceção no animal n 1 , onde a total recuperação do apoio foi em torno de 60 dias de pós-operatório.

\section{Discussão e Conclusão}

A osteocondrite dissecante é uma afecção que acomete animais em desenvolvimento e principalmente as raças gigantes e de grande porte. $O$ tratamento convencional consiste na realização de artrotomia para a remoção do retalho de cartilagem e curetagem do osso subcondral ${ }^{12}$. A artroscopia na espécie canina vem ganhando popularidade entre os ortopedistas e, uma de suas principais indicações é o diagnóstico e tratamento de osteocondrite dissecante ${ }^{2,10}$. É sabido que a técnica artroscópica não é um procedimento fácil, requerendo intenso treinamento e dedicação ${ }^{4}$, pôde-se constatar em nosso estudo também.

A artroscopia possibilita o exame de toda a articulação com visibilização da bainha do tendão bicipital e do compartimento medial ${ }^{10}$. Observaram-se estas e demais estruturas intraarticulares com relativa facilidade.

Dentre os procedimentos que requerem maior habilidade está a triangulação que consiste no posicionamento de um instrumento dentro de uma articulação de um ângulo enquanto o cirurgião olha através do artroscópio de um outro ângulo?. Para a realização da artroscopia em cães existe uma curva de aprendizado, mesmo para cirurgiões experientes em métodos tradicionais ${ }^{3,6}$. Neste estudo foram vivenciadas as dificuldades mencionadas, sendo a realização da triangulação para a confecção do portal instrumental a de maior dificuldade.

Para a abordagem da articulação supra citada foram descritos vários portais ${ }^{5,8,9,10,11,12}$. Dentre as abordagens utilizadas no presente trabalho acredita-se que a confecção do portal instrumental em posição caudal ao portal artroscópico seja mais adequada para a remoção de fragmentos de cartilagem na porção caudal da articulação, enquanto que a posição mais cranial se preste principalmente para a remoção de fragmentos livres próximos a bainha do tendão bicipital.

A infiltração periarticular é uma 
complicação trans-operatória que dependendo da intensidade pode comprometer o prosseguimento do exame artroscópico conseqüente a colapso da cápsula articular e dificuldade de individualização dos pontos de referência para a confecção dos portais ${ }^{8,9,10,12}$. Foi observada em todos os animais, todavia apesar de promover transtorno transoperatório foi sem maiores conseqüências durante o pós-operatório, tendo resolução espontânea em até 24 horas.

A lesão iatrogênica da cartilagem articular é uma complicação trans-operatória que é minimizada com o crescer da experiência ${ }^{2}$. Semelhante a Van Ryssen, Van Bree e Missinne $e^{8}$ esta não trouxe maiores conseqüências no retorno a função do membro para os animais estudados.

O deslocamento do artroscópio ou instrumental prematuramente é uma dificuldade técnica relatada ${ }^{8}$. Constatou-se dificuldade em reposicionar o instrumental ou artroscópio dentro da articulação principalmente em articulações com infiltração periarticular. A utilização de cânulas para a colocação dos instrumentos é contraditória entre os autores ${ }^{2,5}$; e estas têm que ser removidas conjuntamente com o retalho de cartilagem, dependendo de sua dimensão.

Van Ryssen, Van Bree e $\mathrm{Vyt}^{12} \mathrm{e}$ colaboradores relataram inicialmente um estudo em cães portadores de osteocondrite dissecante onde prevaleceu a artroscopia diagnóstica. Apesar de haver a necessidade de se realizar a artrotomia na grande parte dos animais para a remoção do retalho cartilagíneo a artroscopia trouxe informações importantes como número e localização dos retalhos e condição geral da articulação quanto a cartilagem e membrana sinovial. A artroscopia permite uma minúcia de detalhes que resulta em um diagnóstico e tratamento mais acurados ${ }^{1,7}$.

\section{Agradecimentos}

Apoio finaceiro FAPESP.

\title{
The use of arthroscopy on osteochondritis dissecans of the shouder
}

\begin{abstract}
The purpose of this research was to evaluate the use of arthroscopy in dogs with osteochondritis dissecans of the shoulder. We have analysed the possibility to see the structures into the joint, changes of the cartilage, synovial membrane and complications. During the arthroscopic procedure occurred periarticular infiltration, iatrogenic lesions of the cartilage, difficulty to do the arthroscopic portal, instrumental portal, triangulation and premature removal of the arthroscope. All the operated animals had sinovial hiperplasia. The cartilage lesions were chondromalacia, erosion, eburnation, osteophyte, fibrillation, flap and joint mice. The arthroscopy brought us important informations about number and place of the flaps and joint mice as well as general condition of the joint. The removal of the flap or joint mice by arthroscopy requires more hability than that for diagnostic arthroscopy, so the surgeon needs to have more experience.
\end{abstract}

Key-words:

Arthroscoy. Osteochondritis dissecans. Shoulder.

\section{Referências}

1 BEALE, B. S.; HULSE, D. A.; SCHULZ, K. S.; WHITNEY, W. O. Small animal arthroscopy. Philadelphia: W. B. Saunders, 2003. 223 p.

2 ROCHAT, M. C. Arthroscopy. Veterinary Clinics of North America: Small Animal Practice, v. 31, n. 4, p.
$761-787,2001$

3 TAYLOR, R. A. Arthroscopy. In: TAMS, T. R. Small animal endoscopy. 2. ed. St. Louis: Mosby, 1999, p. 461-470. 
4 VAN BREE, H. J. J.; VAN RYSSEN, B. Diagnostic and surgical arthroscopy in osteochondrosis lesions. The Veterinary Clinics of North America: Small Animal Practice, v. 28, n. 1, p. 161-189, 1998.

5 MC CARTHY, T. C. Arthroscopy. In: FREEMAN, L. J. Veterinary endosurgery. St Louis: Mosby, 1999. p. $237-$ 250 .

6 ABERCROMBY, R. Examination of arthroscopy as a clinical tool in small animal practice. Journal of Small Animal Practice, v. 38, n. 4, p. 174-178, 1997.

7 VAN GESTEL, M. A. Diagnostic accuracy of stifle arthroscopy in the dog. Journal of the American Animal Hospital Association, v. 21, n. 6, p. 757-763, 1985.

8 VAN RYSSEN, B.; VAN BREE, H. J. J.; MISSINNE, S. Successful arthroscopic treatment of shoulder osteochondrosis in the dog. Journal of Small Animal Practice, v. 34, n. 10, p. 521-528, 1993.

9 PERSON, M. W. Arthroscopy of the canine shoulder joint. Compendium of Continuing Education for the Practicing Veterinarian, v. 8, n. 8, p. 537-548, 1986.

10 BARDET, J. F. Traitement de l'ostéochondrite disséquante de l'épaule chez le chien par arthroscopie: étude rétrospective de 29 cas. Pratique Medicale et Chirurgicale de L'animal de Compagine, v. 30, n. 6, p. 685-694, 1995

11 GORING, R. L.; PRICE, C. Artroscopical examination of the canine scapulohumeral joint. Journal of the American Animal Hospital Association, v. 23, n. 5, p. 551-555, 1987.

12 VAN RYSSEN, B.; VAN BREE, H. J. J.; VYT, P. Arthroscopy of the shoulder joint in the dog. Journal of the American Animal Hospital Association, v. 29 n. 2 , p. $101-105,1993$.

13 MARTINI, F. M.; PINNA, S.; DEL BUE, M. A simplified technique for diagnostic and surgical arthroscopy of the shoulder joint in the dog. Journal of the Small Animal Practice, v. 43, n. 1, p. 7-11, 2002.

14 PIERMATTEI, D. L.; GREELEY, R. G. An atlas or surgical approaches to the bones of the dog and cat. 2 . ed. Philadelphia: W. B. Saunders, 1979. p. 59-76. 